\title{
An integrated model combining the ECM and the UTAUT to explain users' post-adoption behaviour towards mobile payment systems
}

\author{
Sindhu Singh \\ K.J. Somaiya Institute of Management Studies \& Research \\ India \\ sindhusingh@somaiya.edu
}

\section{Abstract}

Technological progression in mobile phones has increased the popularity of mobile payments. Users can shop online through a mobile device, which is time saving and convenient. Mobile payment systems involve ongoing interactions between users and payment providers. The initial acceptance of mobile payment systems has been studied extensively, but few studies have attempted to understand users' post-adoption behaviour. This study employs an integrated model with the unified theory of acceptance and use of technology (UTAUT) framework and the expectation confirmation model (ECM), along with two additional constructs: perceived security and trust. The empirical results show that the integrated model has a higher predictive power to explain continuance intentions for using mobile payment systems with significant factors of satisfaction, trust, performance expectancy, and effort expectancy. This study confirmed that the UTAUT model could be extended to explain postadoption behaviour towards mobile payment systems. The study's findings have theoretical and practical value to further the understanding of pre- and post-adoption behaviour towards mobile payment systems.

Keywords: mobile payment systems; continuance intention to use; UTAUT; ECM; postadoption; India

\section{Introduction}

Smartphone usage has increased tremendously due to price reductions and the increasing speeds of the mobile internet. Mobile phones are now ubiquitous devices, offering entertainment, education, personal assistants and various options for conducting financial transactions. Technological progression in mobile phones has increased the popularity of mobile payments, which are widely used in e-commerce and in-store transactions and even for utility bill payments. The growth of mobile commerce and the establishment of policies to enable cashless payments in both developed and emerging economies have also supported these trends. Mobile payments allow users to conduct transactions on their mobile devices; the convenience of this approach is enticing a growing number of people to shop online.

With its unparalleled convenience and anytime and anywhere payment options, mobile payment systems will continue their rapid growth in the foreseeable future. Users of mobile wallets reached approximately 2.1 billion in 2019 (Mobile Payments World, 2019). China is ahead of other countries in mobile payment usage, followed by India and several African countries (Gerban, 2019). In India, mobile phone penetration is high, and people prefer smartphones over computers for buying and selling online (Adhikary, 2018). 
Consumers have a multitude of choices when it comes to mobile payments, and they can take advantage of cash discounts and other offers. While mobile payments offer tremendous convenience, threats such as mobile device theft, loss of personal information and privacy incursions may induce fear in potential users (Fan, Shao, Li, \& Huang, 2018; Iman, 2018). Researchers have extensively studied the initial acceptance of mobile payments and have explored various antecedents to initial adoption (Fan et al., 2018; Hampshire, 2017; Oliveira, Thomas, Baptista, \& Campos, 2016; Phonthanukitithaworn, Sellitto, \& Fong, 2015; Schierz, Schilke, \& Wirtz, 2010). Mobile payment systems involve ongoing interactions between users and payment providers, and solid relationships are essential to ensuring customers' continuous usage, particularly in highly competitive contexts. For example, cutthroat competition exists in the mobile wallet industry, with extremely low switching costs for customers (Zhou, 2013). Hence, the critical challenge for mobile payment networks is to retain customers. In the literature on mobile payment systems, studies on users' post-adoption behaviour are scarce (Cao, Yu, Liu, Gong, \& Adeel, 2018; Chen \& Li, 2017; Zhou, 2013). Additional studies in this area will strengthen the theoretical foundation and inform practical implementation. This study addressed this research gap by studying continuous intentions to use mobile payment systems and by developing an integrated model with the expectationconfirmation model (ECM) (Bhattacherjee, 2001) and the unified theory of acceptance and use of technology (UTAUT) framework (Venkatesh, Morris, Davis, \& Davis, 2003).

This study contributes to the research on mobile payment adoption and management of mobile payment systems. The theoretical model developed in this study sheds light on the post-adoption behaviour related to these systems. The initial adoption of mobile payment systems (Baabdullah, Alalwan, Rana, Kizgin, \& Patil, 2019; Oliveira et al., 2016; Teo, Tan, Ooi, Hew, \& Yew, 2015) has been studied using the UTAUT (Venkatesh et al., 2003) and the UTAUT2 (Venkatesh, Thong, \& Xu, 2012) frameworks. However, few studies have used these models to investigate mobile payment post-adoption behaviour. The present study addresses this research gap, extending the UTAUT model to post-adoption behaviour and adding the constructs of trust and perceived security to explore users' continuance intentions. This study's theoretical contribution is in developing a novel integrated model to explore an understudied area. This study's findings have both theoretical and practical value, furthering the understanding of pre- and post-adoption behaviour with respect to mobile payments.

\section{Literature Review}

\subsection{Mobile Payments}

Mobile payment systems allow payments for goods and services through mobile networks via smartphones (Dahlberg, Mallat, Ondrus, \& Zmijewska, 2008). Ghezzi, Renga, Balocco, and Pescetto $(2010$, p. 5) defined a mobile payment system as 'a process in which at least one phase of the transaction is conducted using a mobile device (such as mobile phone, smart phone, PDA, or any wireless-enabled device) capable of securely processing a financial transaction over a mobile network or via various wireless technologies (Bluetooth, radio frequency identification (RFID), near field communication (NFC), etc.)'.

Mobile payments can utilise any of the following systems: Short Message Service (SMS), Near Field Communication (NFC), Wireless Application Protocol (WAP) and Quick Response Code (QR) (Chen \& Li, 2017). In SMS-based mobile payments, customers initiate payments through SMS, and merchants are notified when payments are successful. The payment is then deducted 
from the customer's monthly phone bill (Ondrus \& Pigneur, 2006). NFC-based payment systems require that customers' mobile phones are equipped with an NFC-enabled chip, and merchants with card readers can initiate payment processes (Li, Liu, \& Heikkilä, 2014). The WAP-based mobile payment systems work in two ways. In one, customers use mobile browsers to initiate payments through banks at which they registered for mobile payments. Alternatively, they can download mobile apps (such as Paytm and PhonePe in India) and link these apps with their bank accounts. Then, they can use money in their bank accounts to pay for products and services (Isaac \& Sherali, 2014). In QR-based payments, customers open mobile payment apps and scan the QR code to initiate payments (Lee, Cho, \& Jun, 2011).

Some of the well-known mobile wallet apps are Apple Pay, Google Pay and Samsung Pay, which are integrated with the banking systems of their resident countries. Apple Pay works only with Apple devices, uses only NFC mechanisms, and uses encryption techniques and tokenisation for secure transactions (Kang, 2018). Using any of these payment mechanisms, the mobile wallet user can add their debit/credit card details to their wallets, after which the mobile wallet providers contact the card issuer for authentication and add the card information to the wallets after successful authentication (Wang, Hahn, \& Sutrave, 2016). Samsung Pay uses, in addition to NFC, magnetic secure transmission (MST), which allows mobile wallet users to use Samsung Pay in store even when retailers have not upgraded to an NFC reader, thereby ensuring the compatibility and convenience of the payment method (Kang, 2018; Wang et al., 2016).

Google Pay, formerly known as Android Pay, supports only NFC technologies and works with any Android devices for in-store and peer-to-peer payments (Kang, 2018). Along with in-store and online payments, in India, Google Pay can be linked to bank accounts that support unified payment interface (UPI) for direct transactions instead of adding money to the wallet. Similarly, PayPal's mobile app offers various services, such as send and receive money, by linking PayPal accounts with banks as well as online and in-store payments. In addition, PayPal accounts can be linked to Google Pay, and the PayPal app allows access to these accounts from iPhones/Android phones as well as the ability to transfer funds through the linked bank account or through attached credit/debit cards. This study considers both types of mobile payments: payments initiated through mobile apps, and payments conducted through mobile browsers (Figure 1). 


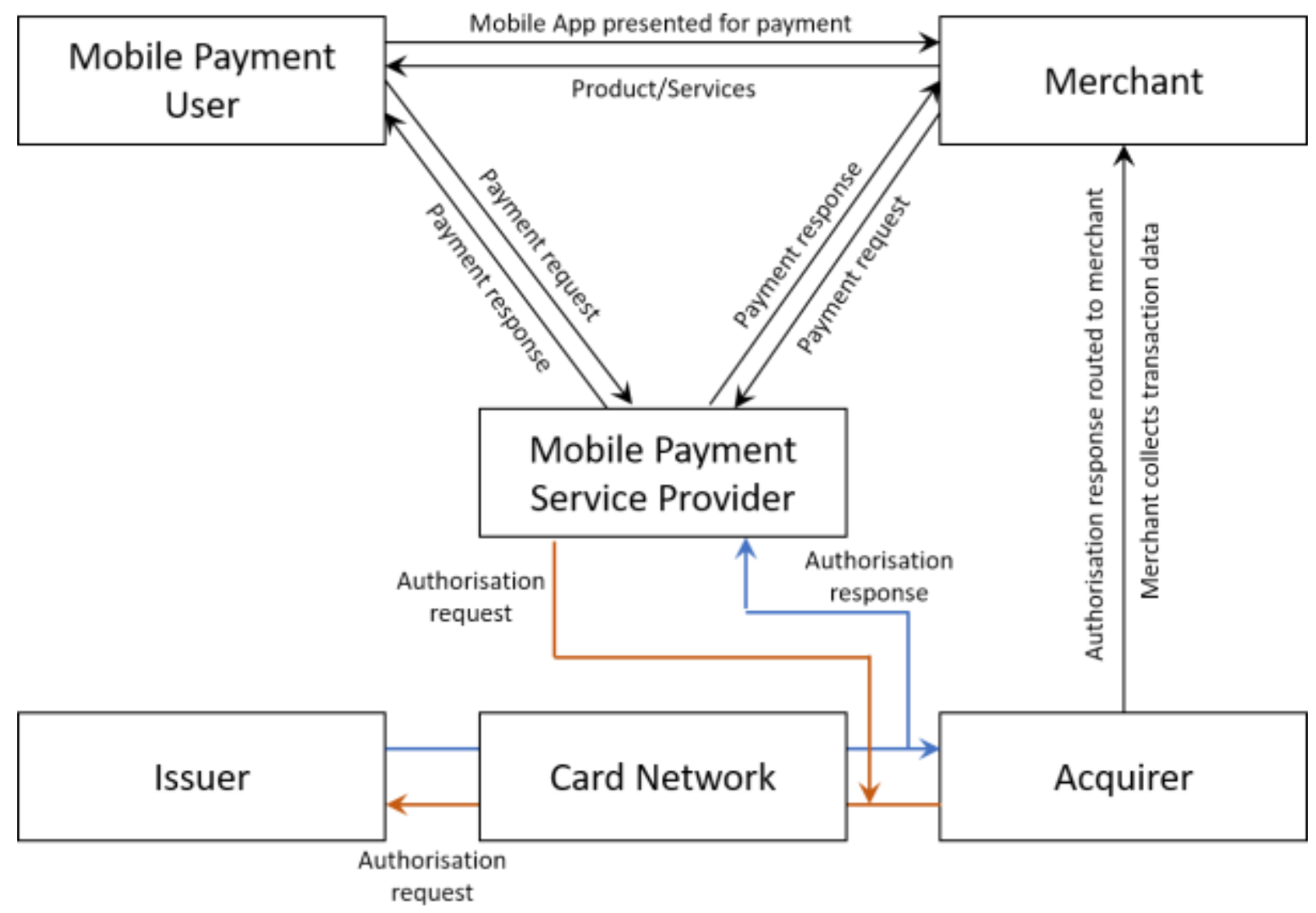

Figure 1: Mobile Payment Process (Source: Wang, Hahn, E Sutrave (2016))

\subsection{Post-adoption of Mobile Payments}

Many studies of users' initial adoption of mobile payments appear in the literature, and these studies have identified antecedents of mobile payments initial adoption, such as performance expectancy, perceived security, social influence, compatibility and trust (Fan et al., 2018; Hampshire, 2017; Kim, Mirusmonov, \& Lee, 2010; Musa \& AIShare, 2015; Oliveira et al., 2016; Ramadan \& Aita, 2018). Conversely, only a few studies have focused on users' post-adoption behaviour towards mobile payment systems. Among these few studies, Cao, Yu, Liu, Gong, and Adeel (2018) used a trust transfer perspective to investigate the continuous intention to use mobile payments in 219 mobile payment users in China. Their study revealed that trust transfer positively influenced continuous intention through satisfaction. Kumar, Adlakaha, and Mukherjee (2018) studied continuance intention to use M-wallets in 265 mobile wallet users in India using the technology acceptance model (TAM) and the ECM with the additional constructs of perceived security, trust and grievance redressal. Their results revealed that grievance redressal, trust and satisfaction influenced continuance intention. In China, Chen and $\mathrm{Li}$ (2017) studied the continuous intention to use mobile payments in 38 interviewees (qualitative analysis) and 243 survey respondents (quantitative analysis) using IT continuance theory and the risk-trust and affect-cognition framework. In this study, satisfaction and postadoption perceived usefulness significantly impacted the continuance intention to use mobile payments. Lu, Wei, Yu, and Liu (2016) examined the post-usage of m-payments in 724 mobile payment users in China using expectation-confirmation theory. Their findings revealed that post-usage privacy protections and social influence impacted continued usage, whereas postusage mobility impacted satisfaction. Other findings from their research were that espoused 
cultural values acted as antecedents to social influence and post-usage mobility. Yuan, Liu, Yao, and Liu (2014) studied the continuance intention to use mobile payments in 434 users in China using an integrated model comprising the TAM, task-technology fit and perceived risk with the ECM. Their findings showed that satisfaction, perceived risk, perceived usefulness and perceived task-technology fit were the main drivers of continuance intention. Zhou (2013, 2014) examined the factors of continuance intention to use mobile payments in 195 respondents in China using the IS success model (Delone \& Mclean, 1993) and flow theory. His findings indicated that trust, flow and satisfaction influenced continuance intention; service quality influenced trust; system quality affected satisfaction; and information quality and service quality affected flow (Zhou, 2013, 2014).

There have been a limited number of studies on post-adoption behaviour towards mobile payment systems, and the majority of these studies have been conducted in China (Cao et al., 2018; Chen \& Li, 2017; Lu, Wei, Yu, \& Liu , 2016; Yuan, Liu, Yao, \& Liu, 2014; Zhou, 2013). More studies are needed to shed light on users' post-adoption behaviour, which often changes depending on the cultural, economic and research context. Hence, in the interest of generalisability, adoption behaviour should be studied in other parts of the world. The initial adoption of mobile payment systems (Baabdullah et al., 2019; Oliveira et al., 2016; Teo et al., 2015) has been studied using the UTAUT (Venkatesh et al., 2003) and the UTAUT2 (Venkatesh et al., 2012) frameworks, but few studies have used this model to study post-adoption behaviour. Mobile payment is a convenient option for conducting financial transactions, but it is still in its infancy, and not much is known about post-adoption behaviour. Ensuring the loyalty of customers, who expect user-friendly interfaces for their mobile payment wallets and the option to choose from a wide variety of mobile payment solutions, is an enormous challenge for providers. Thus, it is critical to examine the influence of usage factors, such as performance expectancy and effort expectancy, in post-adoption behaviour towards mobile payment systems.

\section{Theoretical Model and Hypotheses Development}

This study used an integrated theoretical model (Figure 2) based on the UTAUT (Venkatesh et al., 2003) and the ECM (Bhattacherjee, 2001). It added two additional constructs, perceived security and trust, with continuance intention to use mobile payment systems as the dependent variable. Mobile payment systems are still emerging. To more fully capture the unique characteristics of this new technology and to better understand its continuous acceptance, it is preferable to integrate multiple theoretical frameworks (Apanasevic, Markendahl, \& Arvidsson, 2016; Oliveira et al., 2016; Zhou, 2013).

\subsection{Expectation-Confirmation Model}

The Expectation-Confirmation Model (ECM) (Bhattacherjee, 2001) posits that users' continuance intention for any information system is influenced by their satisfaction and their perceived usefulness of continued usage. Satisfaction results when expectations from prior use of information systems and from perceived usefulness are confirmed (Bhattacherjee, 2001). The post-acceptance of any IS depends upon the user satisfaction, which impacts continuance (2001). Continuance intention is defined as 'users' intention to continue using IS' (2001, p. 359). The ECM has been used extensively to study the relationship between satisfaction and continuance intention to use various information systems (Shang \& Wu, 2017; Zhang, Lu, Gupta, \& Gao, 2015). However, there have been limited studies in the area of mobile payment 
usage (Susanto, Chang, \& Ha, 2016). To understand post-adoption behaviour towards mobile payment systems, satisfaction and continuance intention were used as dependent variables, and the ECM served as the theoretical basis of the research model.

\subsection{Unified Theory of Acceptance and Use of Technology}

The Unified Theory of Acceptance and Use of Technology (UTAUT) (Venkatesh et al., 2003) was developed by assimilating elements from eight widely accepted models of information systems (IS). The core constructs of the model were performance expectancy, effort expectancy, social influence and facilitating conditions, all of which influence behavioural intention to use technology, while the moderators were age, experience, gender and the voluntariness of use (Venkatesh et al., 2003). The UTAUT explains higher variance in behavioural intentions compared to the eight other models (Venkatesh et al., 2003). Subsequently, many studies have used the model (Hoque \& Sorwar, 2017; Khalilzadeh, Ozturk, \& Bilgihan, 2017). Although the model has been widely utilised to explore behavioural intentions to use mobile payment systems (Cao \& Niu, 2019; Teo et al., 2015), it has seldom been employed to study post-adoption behaviour (Oliveira et al., 2016). While the derivation of the UTAUT model has demonstrated user adoption of technologies, which is in effect a single choice, mobile payment continuance intention depends on users' ongoing choices (Dwivedi, Rana, Jeyaraj, Clement, \& Williams, 2017). Thus, this research addresses a gap and extends the UTAUT and ECM frameworks (Bhattacherjee, 2001) to explore customers' postadoption behaviour regarding mobile payment services.

The adapted theoretical model used performance expectancy and effort expectancy from the UTAUT model (Venkatesh et al., 2003). Facilitating conditions and social influence were not used, since these constructs are more relevant to the initial adoption process than to continuance intention. This theoretical model integrated confirmation, satisfaction and continuance intention from the ECM model (Bhattacherjee, 2001) to understand the postadoption behaviour of mobile payment users. Mobile payment systems are vulnerable to various security threats. Therefore, in the post-adoption phase, perceived security is critical. It thus follows that when users trust their mobile payment service provider, usage will increase. This is because each time a user has a positive experience with a mobile payment service provider, it enhances user trust, which accumulates with each positive experience. Positive experiences also strengthen users' confidence in the system's overall security, making it more likely that they will use the system again. Thus, these constructs play a significant role in continuous usage of mobile payment systems. Prior research has confirmed that trust and perceived security can influence decisions to use mobile payment systems (Giovanis, Assimakopoulos, \& Sarmaniotis, 2018; Phonthanukitithaworn et al., 2015; Schierz et al., 2010).The independent variables used in the model are described in the next section.

\subsection{Performance Expectancy}

In the UTAUT model (Venkatesh et al., 2003, p. 447), performance expectancy is defined as 'the degree to which an individual believes that using the system will help him or her to attain gains in job performance'. In the UTAUT2 model (Venkatesh et al., 2012, p. 159), performance expectancy in a consumer context 'is defined as the degree to which using technology will provide benefits to consumers in performing certain activities'. Mobile payment systems offer customers greater convenience by allowing them to conduct financial transactions through their personal mobile device anytime and anywhere. When customers realise this utility value 
of the mobile payment system, their performance expectancy beliefs also increase (Oliveira et al., 2016; Zhou, 2014). Hence, the following hypothesis is proposed.

H1: Performance expectancy significantly influences the continuance intention to use mobile payment systems.

\subsection{Effort Expectancy}

In the UTAUT model (Venkatesh et al., 2003, p. 447), effort expectancy is defined as 'the degree of ease associated with the use of the system'. Venkatesh et al. (2012, p. 159) adapted this construct in the UTAUT2 model, defining it as 'the degree of ease associated with consumers' use of technology'. Customers expect their mobile payment system to have a simple interface, which increases the utility value of the system. User-friendly payment systems not only promote initial acceptance, they also play a major role in continuance intention. Past research has confirmed that effort expectancy influences the initial adoption of mobile payment systems (Cao \& Niu, 2019; Teo et al., 2015). Hence, the following hypotheses are proposed.

H2: Effort expectancy significantly influences the continuance intention to use mobile payment systems.

H2a: Effort expectancy significantly influences the performance expectancy of mobile payment systems.

\subsection{Perceived Security}

Fan, Shao, Li, and Huang (2018, p. 526) defined perceived security in a mobile payment context as 'the degree to which people believe that their property and information privacy is secure while using mobile payment'. Customers will use a mobile payment system only when they perceive it has adequate security mechanisms (Iman, 2018), and robust security features will enhance customers' trust in their mobile payment system providers. It follows, then, that customers are more likely to patronise mobile payment service providers when the providers are trustworthy and verified. Furthermore, advanced security features in mobile payment systems increase users' continuance intention to use the systems. Hence, the following hypotheses are proposed.

H3: Perceived security significantly influences the continuance intention to use mobile payment systems.

H3a: Perceived security significantly influences customer trust in the mobile payment systems.

\subsection{Trust}

Mobile payment system customers place a high level of importance on trust. After customers initially use a system, their further usage will depend on trust-building. Trust has various definitions in the existing literature. McKnight, Choudhury, and Kacmar (2002, p. 336) described it as 'trusting beliefs lead to trusting intentions, which in turn result in trust-related behaviours. Previous studies have verified that trust is a significant predictor of continuance intention to use mobile payments (Zhou, 2013, 2014). Trust associations between customers and mobile payment service providers significantly affect customers' decisions to continue using the mobile payment systems. Hence, the following hypothesis is proposed.

H4: Trust significantly influences continuance intention to use mobile payment systems. 


\subsection{Satisfaction}

In mobile payment systems, customer satisfaction leads to continuance intention to use mobile payment systems. Satisfaction follows a positive outcome from the initial acceptance of mobile payment systems and has many definitions in the existing literature. For example, in marketing, it has been defined as 'the consumer's sense that consumption provides outcomes against a standard of pleasure versus displeasure' (Oliver, 1999, p. 34). In an electronic marketplace, satisfaction is referred to as e-satisfaction and defined as 'the contentment of the customer with respect to his or her prior purchasing experience with a given electroniccommerce firm' (Anderson \& Srinivasan, 2003, p. 125). In the IS field, Delone and McLean (2003, p. 25) defined user satisfaction as encompassing 'the entire customer experience cycle from information retrieval through purchase, payment, receipt, and service'. Previous studies have reported that satisfaction is a strong predictor of continuance intention (Cao et al., 2018; Chen \& Li, 2017; Zhou, 2013). Hence, the following hypothesis is proposed.

H5: Satisfaction significantly influences the continuance intention to use mobile payment systems.

\subsection{Relationships Between Performance Expectancy, Confirmation and Satisfaction}

Bhattacherjee (2001, p. 359) defined confirmation as a user's 'perception of the congruence between the expectation of IS use and its actual performance'. The ECM (Bhattacherjee, 2001) suggests that satisfaction is determined by confirmation of users' expectations of IS use and its perceived usefulness. In the mobile payment systems context, customers' expectations are confirmed with continued usage, and their post-adoption usage of mobile payment systems increases their utilitarian expectation in terms of performance expectancy and satisfaction. When customers have their mobile payment systems usage experience confirmed, performance expectancy and satisfaction with the system are engendered. Hence, the following hypotheses are proposed.

H6: Confirmation significantly influences performance expectancy for mobile payment systems.

H7: Confirmation significantly influences satisfaction with using mobile payment systems.

H8: Performance expectancy significantly influences satisfaction with using mobile payment systems. 


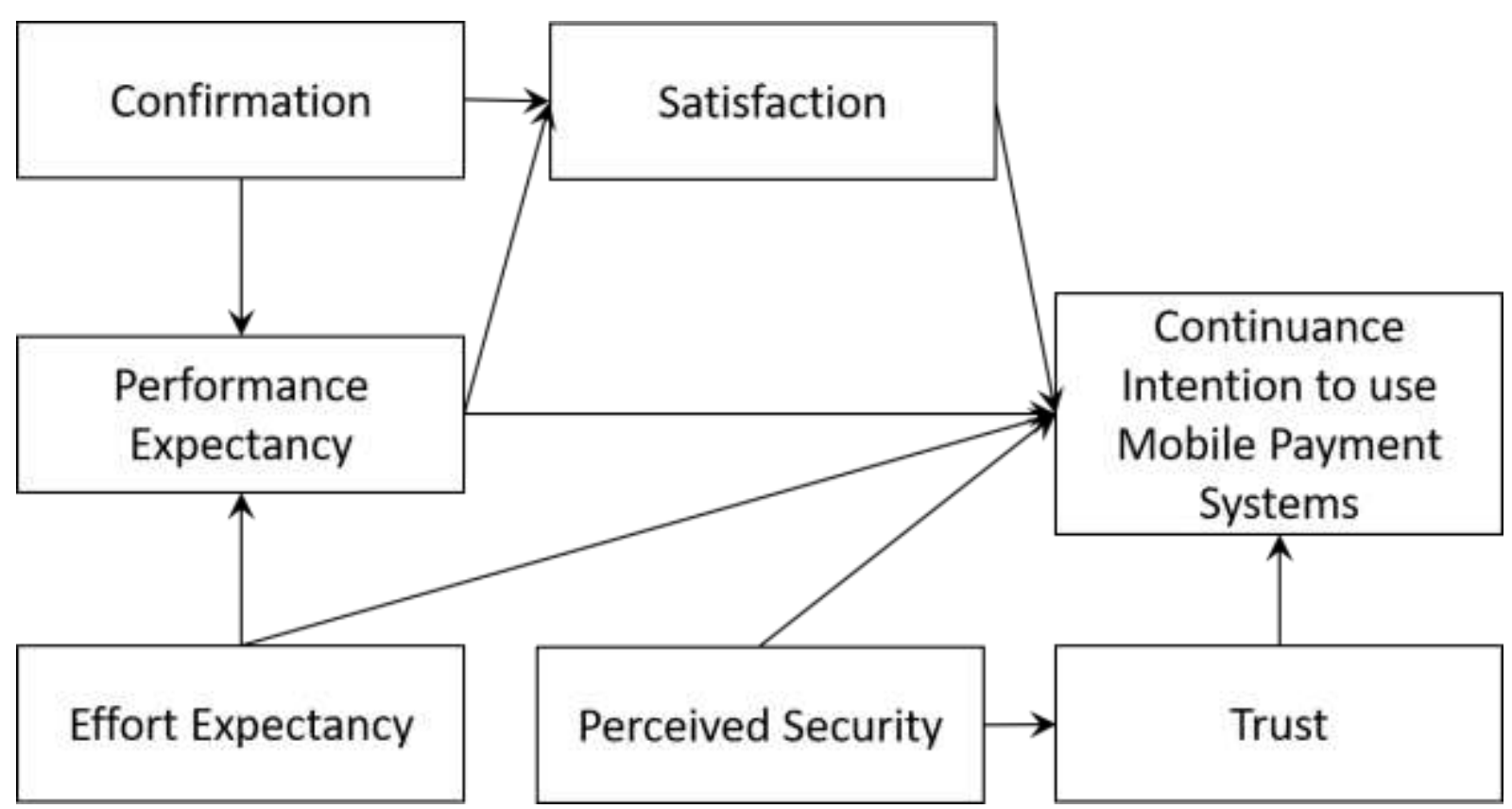

Figure 2: Theoretical Model

\section{Research Methodology}

\subsection{Variable Measurement}

The variables used in the theoretical model were measured using validated items from prior research (Appendix A). These items were reworded to suit the current study context. This study used a 5-point Likert scale to measure the items, since this scale is widely used in marketing and social science research (Garland, 1991), where 1 indicates 'strongly disagree' and 5 indicates 'strongly agree'. In the questionnaire developed to measure and test the theoretical model, 28 items were used.

To test the applicability of the instrument in a mobile payment adoption context, the questionnaire was shown to several academics and practitioners in the IS and marketing fields. It was also pretested with 10 mobile payment customers to ensure completeness and correctness, and the feedback from both groups was incorporated into the final questionnaire.

\subsection{Sample Profile and Data Collection}

This study followed a quantitative research approach, using a questionnaire to collect data. The sample population identified were mobile payment users who used mobile payment systems at least once. A qualifying question was used to identify the target respondents: 'Do you use any mobile payment system at least once?'. Convenience sampling (a non-probability sampling method) was used to identify respondents. Given the lack of availability of the mobile payment customer list and the time and cost of collecting the response from each customer, this study used convenience sampling as a method for collecting the responses from the survey questionnaire. Earlier studies on mobile payment adoption from both developed and developing countries also used non-probability sampling to collect responses (Fan et al., 2018; Chen \& Li, 2017; Kumar, Adlakaha, \& Mukherjee, 2018). This research study used various multivariate techniques, and 28 items were used to measure the various constructs in the theoretical model. In addition, the following guidelines suggested by Hair et al. (2010) were also followed: 10 observations per item, and a minimum sample size of 280 . The data 
collection took place in Mumbai, the financial capital, and in one metropolitan region of India. A total of 500 questionnaires were distributed, and the survey was conducted over a period of three months, from May to July 2019. The study's purpose was explained to respondents, and assurances were made that survey responses would be used only for the current study. Participation in the survey was voluntary, and respondents were free to skip questions they did not wish to answer. The questionnaire was distributed to participants in offline and online formats. Some offline or paper versions were distributed to post-graduate students, faculty and supporting staff at a business management school in Mumbai, yielding 100 collected responses. In the online version, a Google form link was sent through personal email and WhatsApp contacts. A total of 400 questionnaires were collected from both the online and offline methods, out of which 370 were completed and thus deemed usable. The distribution of the questionnaires and the completed and usable responses were outlined in Table 1. After removing incomplete forms and excluding those who had not used mobile payments at least once, the response rate was determined to be $74 \%$. A chi-square test was conducted which demonstrated that no significant differences exist among gender, age, education, and income between the online and offline groups at the $5 \%$ significance level.

\begin{tabular}{|l|c|c|c|}
\hline Type of Survey & Distributed Questionnaires & Completed Responses & Usable Responses \\
\hline Offline & 150 & 100 & 100 \\
\hline Online & 350 & 300 & 270 \\
\hline Total & 500 & 400 & 370 \\
\hline
\end{tabular}

Table 1: Distribution of Questionnaires

Data were analysed using the Statistical Package for Social Sciences (SPSS) version 21.0. Structural equation modelling (SEM) was used to test this study's theoretical model. This technique measures the hypothesised causal relationships among multiple variables simultaneously and estimates the strength of interrelationships among latent constructs. Path analysis models include covariance-based SEM (CB-SEM) or partial least squares SEM (PLSSEM) (Hair Jr, Hult, Ringle, \& Sarstedt, 2016), with CB-SEM being more suitable for theory testing, and PLS-SEM being more appropriate for modelling the theoretical relationships among latent constructs (Hair Jr et al., 2016). PLS-SEM can model latent constructs for small and medium sample sizes and works well in the presence of data non-normality (Chin, Marcolin, \& Newsted, 2003). This study was exploratory in nature and prediction-based, integrating two theoretical perspectives, the UTAUT model and the ECM, along with perceived security and trust in the context of mobile payment systems. The following requirements of this study met the guidelines suggested by Hair, Risher, Sarstedt, and Ringle $(2019$, p. 5) for choosing PLS-SEM as the suitable method:

- $\quad$ This study tested a theoretical framework, from a prediction perspective, that integrated two theoretical perspectives, the UTAUT model and the ECM, to predict users' continuance intention to use mobile payment systems.

- $\quad$ This study assessed the mediation effect in the structural model with the presence of multiple mediators and used PLS-SEM, as 'PLS-SEM is superior to regression analysis when assessing mediation' (Hair, Sarstedt, \& Ringle, 2019, p. 567).

- $\quad$ The analysis included the structural model, which was complex and consisted of seven constructs, 28 indicators and model relationships. 
- $\quad$ The objective of the study was to explore theoretical extensions of well-established theories, such as the UTAUT and the ECM, in the mobile payment context, along with the additional constructs of perceived security and trust.

The study used PLS-SEM path modelling with Smart PLS 3 software (Ringle, da Silva, \& Bido, 2015) to analyse the measurement model and structural paths of the theoretical model.

\section{Results}

The mobile payment usage profiles of the 370 respondents were analysed (Table 2). Among respondents, $55.9 \%$ were male and $44.1 \%$ were female. Around $70.3 \%$ of the respondents reported regularly using mobile payment systems for various payment transactions. Further, the results showed that Paytm was the dominant mobile wallet compared to others, such as Mobikwik and Freecharge, with a $78.38 \%$ usage rate. The majority of respondents reported using mobile payment systems for small-value transactions, with frequent usage for mobile recharges, grocery stores, online shopping and paying bills.

\begin{tabular}{|c|c|c|c|}
\hline Variable & Category & Frequency & Percentage (\%) \\
\hline \multirow{2}{*}{ Gender } & Male & 207 & 55.9 \\
\hline & Female & 163 & 44.1 \\
\hline \multirow{4}{*}{ Age } & $15-25$ & 179 & 48.4 \\
\hline & $26-35$ & 149 & 40.3 \\
\hline & $36-45$ & 28 & 7.6 \\
\hline & Above 45 & 14 & 3.7 \\
\hline \multirow{5}{*}{ Educational qualification } & 10th & 3 & 0.8 \\
\hline & 12th & 17 & 4.6 \\
\hline & Diploma & 19 & 5.1 \\
\hline & Degree & 211 & 57.0 \\
\hline & Postgraduate & 120 & 32.4 \\
\hline \multirow{3}{*}{ Income } & Less than 5 lakhs & 103 & 27.84 \\
\hline & Between 5-10 lakhs & 165 & 44.59 \\
\hline & Above ten lakhs & 102 & 27.57 \\
\hline \multirow{4}{*}{ Frequency of mobile payment usage } & Daily & 27 & 7.3 \\
\hline & 1-2 times a week & 195 & 52.7 \\
\hline & 3-6 times a week & 101 & 27.3 \\
\hline & Once a month & 47 & 12.7 \\
\hline \multirow{4}{*}{ Mobile payment option } & Paytm & 290 & 78.38 \\
\hline & Mobikwik & 45 & 12.16 \\
\hline & Freecharge & 26 & 7.03 \\
\hline & Others & 9 & 2.43 \\
\hline \multirow{3}{*}{ Size of transactions } & Less than Rs 100 & 13 & 3.5 \\
\hline & Rs 100 to Rs 1000 & 165 & 44.6 \\
\hline & Rs 1001 to less than Rs 5000 & 192 & 51.9 \\
\hline
\end{tabular}

Table 2: Demographic Profile of the Respondents

\subsection{Normality Assessment}

To measure the normality of the survey items of the constructs, the skewness-kurtosis method was used. SPSS 21.0 was used to test the values of skewness and kurtosis. All the values of the measured items had skewness and kurtosis values in the acceptable range, between -2 and +2 (Byrne, 2016; George \& Mallery, 2010; Hair, Black, Babin, \& Anderson, 2010). Hence, the data set followed a univariate normal distribution. To identify the outliers in the data set, Z-scores 
of the variables were calculated, and the acceptable range of values were between -3 and +3 (Kline, 2011). Out of 370 usable data items, six items were identified as having Z-score values above the acceptable range, demonstrating the presence of outliers; these items were thus removed from the data set before further analysis.

\subsection{Common Method Bias}

Survey-based research is vulnerable to common method variance when respondents complete the survey questionnaire themselves (Podsakoff, MacKenzie, Lee, \& Podsakoff, 2003), and for this reason, Harman's single-factor test was conducted to examine common method bias (CMB). In this test, multiple factors were extracted from the factor analysis, and no single factor accounted for major variance. Thus, common method variance was not a major issue in this study.

\subsection{PLS-SEM Model Assessment}

This study used PLS-SEM and the two-step approach suggested by Anderson and Gerbing (1988). First, the measurement model was analysed for reliability and validity. Next, the structural model was analysed to test the hypothesised causal relationships.

\subsubsection{Measurement Model Analysis}

The reliability of the constructs was assessed by computing Cronbach's alpha and composite reliability (CR). The cut-off value recommended for both Cronbach's alpha and composite reliability is 0.70 (Hair et al., 2010). Table 3 shows that all constructs had cut-off values above 0.70 , indicating that all items used in this study had adequate reliability. To check the validity of the constructs, the average variance extracted (AVE) was calculated. This is a complementary measure to composite reliability that reflects the overall amount of variance in the indicators, accounting for the latent construct (Hair et al., 2010). The cut-off value of AVE was above 0.50 (Hair et al., 2019), with all constructs used in this study exceeding the cutoff value (Table 3). All items of the measured constructs (Table 3) had indicator loadings greater than the cut-off value of 0.708 (Hair et al., 2019), meaning that the constructs explained more than $50 \%$ of the indicators' variance, demonstrating the reliability of the constructs' items.

To establish the validity of the measurement model, convergent validity and discriminant validity were estimated. Each construct's composite reliability and AVE were calculated to estimate the convergent validity of the measurement model. Both measurements were above the cut-off value (Fornell \& Larcker, 1981) for the measurement model (Table 3); thus, convergent validity was established for this study. 


\begin{tabular}{|c|c|c|c|c|c|}
\hline Construct & \multicolumn{2}{|c|}{ Item loading } & AVE & Cronbach's Alpha & Composite Reliability \\
\hline \multirow{4}{*}{ Continuance Intention (CI) } & CI1 & 0.851 & \multirow{4}{*}{0.735} & \multirow{4}{*}{0.88} & \multirow{4}{*}{0.917} \\
\hline & $\mathrm{CI} 2$ & 0.856 & & & \\
\hline & $\mathrm{CI} 3$ & 0.898 & & & \\
\hline & CI4 & 0.823 & & & \\
\hline \multirow{3}{*}{ Confirmation (CONF) } & CONF1 & 0.905 & \multirow{3}{*}{0.746} & \multirow{3}{*}{0.829} & \multirow{3}{*}{0.898} \\
\hline & CONF2 & 0.877 & & & \\
\hline & CONF3 & 0.806 & & & \\
\hline \multirow{4}{*}{ Effort Expectancy (EE) } & EE1 & 0.854 & \multirow{4}{*}{0.765} & \multirow{4}{*}{0.898} & \multirow{4}{*}{0.929} \\
\hline & EE2 & 0.89 & & & \\
\hline & EE3 & 0.88 & & & \\
\hline & EE4 & 0.875 & & & \\
\hline \multirow{4}{*}{ Performance Expectancy (PE) } & PE1 & 0.855 & \multirow{4}{*}{0.687} & \multirow{4}{*}{0.847} & \multirow{4}{*}{0.897} \\
\hline & PE2 & 0.815 & & & \\
\hline & PE3 & 0.761 & & & \\
\hline & PE4 & 0.879 & & & \\
\hline \multirow{4}{*}{ Perceived Security (PS) } & PS1 & 0.796 & \multirow{4}{*}{0.721} & \multirow{4}{*}{0.873} & \multirow{4}{*}{0.912} \\
\hline & PS2 & 0.881 & & & \\
\hline & PS3 & 0.882 & & & \\
\hline & PS4 & 0.834 & & & \\
\hline \multirow{3}{*}{ Satisfaction (SAT) } & SAT1 & 0.893 & \multirow{3}{*}{0.815} & \multirow{3}{*}{0.886} & \multirow{3}{*}{0.93} \\
\hline & SAT2 & 0.924 & & & \\
\hline & SAT3 & 0.891 & & & \\
\hline \multirow{6}{*}{ Trust (TRU) } & TRU1 & 0.801 & \multirow{6}{*}{0.695} & \multirow{6}{*}{0.911} & \multirow{6}{*}{0.932} \\
\hline & TRU2 & 0.86 & & & \\
\hline & TRU3 & 0.865 & & & \\
\hline & TRU4 & 0.885 & & & \\
\hline & TRU5 & 0.838 & & & \\
\hline & TRU6 & 0.746 & & & \\
\hline
\end{tabular}

Table 3: Measurement Model Analysis

To compute discriminant validity, as suggested by Fornell and Larcker (1981), one compares the shared variance between the constructs with the AVE from each construct. Discriminant validity was established for this measurement model, as the shared variance between the constructs was lower than the AVE for each construct (Table 4).

\begin{tabular}{|l|l|l|l|l|l|l|l|}
\hline Constructs & CI & CONF & EE & PE & PS & SAT & TRUST \\
\hline CI & $\mathbf{0 . 8 5 7}$ & & & & & & \\
\hline CONF & 0.731 & $\mathbf{0 . 8 6 4}$ & & & & & \\
\hline EE & 0.646 & 0.7 & $\mathbf{0 . 8 7 5}$ & & & & \\
\hline PE & 0.631 & 0.709 & 0.79 & $\mathbf{0 . 8 2 9}$ & & & \\
\hline PS & 0.433 & 0.519 & 0.381 & 0.407 & $\mathbf{0 . 8 4 9}$ & & \\
\hline SAT & 0.789 & 0.707 & 0.625 & 0.597 & 0.439 & $\mathbf{0 . 9 0 3}$ & \\
\hline TRUST & 0.685 & 0.71 & 0.602 & 0.568 & 0.626 & 0.717 & $\mathbf{0 . 8 3 4}$ \\
\hline
\end{tabular}

CI: Continuance Intention; CONF: Confirmation; EE: Effort expectancy; PE: Performance expectancy; PS: Perceived Security; SAT: Satisfaction

Table 4: Discriminant Validity of Measured Items 


\subsubsection{Structural Model Analysis}

To test the theoretical model, a non-parametric bootstrapping method was used with 5,000 samples. The structural model (Figure 3) and the path coefficients are shown in Table 5. The path coefficients were significant for performance expectancy, effort expectancy, trust and satisfaction (hypotheses H1, H2, H4, and H5), indicating significant influences on continuance intention to use mobile payment systems. Effort expectancy significantly influenced performance expectancy, thus validating hypothesis H2a. Perceived security significantly influenced trust, hence validating hypothesis H3a. Performance expectancy and confirmation positively influenced satisfaction, validating hypotheses $\mathrm{H} 7$ and $\mathrm{H} 8$. Confirmation significantly influenced performance expectancy, hence validating hypothesis H6. However, perceived security did not influence continuance intention to use mobile payment systems; thus, hypothesis H3 was rejected. The control variables of age, gender and income did not influence the continuance intention to use mobile payment systems.

The $\beta$ coefficient represents the influence of the independent variable in the theoretical model. Figure 3 shows that performance expectancy $(\beta=0.129, p=0.004)$, effort expectancy $(\beta=0.12$, $\mathrm{p}=0.035)$, trust $(\beta=0.167, \mathrm{p}=0.01)$ and satisfaction $(\beta=0.518, \mathrm{p}=0.000)$ were statistically significant. Among the independent variables, satisfaction demonstrated the highest influence $(\beta=0.518)$ on continuance intention to use mobile payment systems, followed by trust $(\beta=0.167)$, performance expectancy $(\beta=0.129)$ and effort expectancy $(\beta=0.12)$.

Perceived security $(\beta=0.001, p=0.988)$ was not statistically significant - that is, it did not directly influence the dependent variable, continuance intention to use mobile payment systems, but it did have an indirect influence through trust. In the post-adoption of mobile payment systems, customers have sufficient experience and confidence when using their mobile payment system. Hence, they may consider trust as a critical factor in their decision to continue with their mobile payment service providers. Security features, on the other hand, are built into the mobile payment systems. This may be the reason perceived security was not significant.

The $\mathrm{R}^{2}$ value obtained during the structural model analysis represents the total variance explained by the independent variables for the dependent variable. The obtained $\mathrm{R}^{2}$ values were $0.685,0.672,0.517$ and 0.392 for continuance intention, performance expectancy, satisfaction and trust, respectively. Performance expectancy, effort expectancy, trust and satisfaction together explained $68.5 \%$ of the variance in the dependent variable: continuance intention to use mobile payment systems. The ECM model accounted for $51.7 \%$ of the variance explained in continuance intention to use mobile payment systems. Effort expectancy explained $67.2 \%$ of the variance in performance expectancy; whereas perceived security explained $39.2 \%$ of the variance in trust. 


\begin{tabular}{|l|l|l|l|l|}
\hline \multicolumn{1}{|c|}{ Hypotheses } & \multicolumn{1}{|c|}{ Path } & $\begin{array}{c}\text { Path } \\
\text { Coefficient }\end{array}$ & p-values & \multicolumn{1}{c|}{ Result } \\
\hline H1 & PE $\rightarrow$ CI & $0.129^{* *}$ & 0.004 & Accepted \\
\hline H2 & EE $\rightarrow$ CI & $0.12^{*}$ & 0.035 & Accepted \\
\hline H2a & EE $\rightarrow$ PE & $0.576^{* * *}$ & 0.000 & Accepted \\
\hline H3 & PS $\rightarrow$ CI & 0.001 & 0.988 & Rejected \\
\hline H3a & PS $\rightarrow$ TRUST & $0.626^{* * *}$ & 0.000 & Accepted \\
\hline H4 & TRUST $\rightarrow$ CI & $0.167^{*}$ & 0.01 & Accepted \\
\hline H5 & SAT $\rightarrow$ CI & $0.518^{* * *}$ & 0.000 & Accepted \\
\hline H6 & CONF $\rightarrow$ PE & $0.305^{* * *}$ & 0.000 & Accepted \\
\hline H7 & CONF $\rightarrow$ SAT & $0.572^{* * *}$ & 0.000 & Accepted \\
\hline H8 & PE $\rightarrow$ SAT & & $0.189^{* *}$ & Accepted \\
\hline
\end{tabular}

${ }^{*} \mathrm{p}<0.05 ;{ }^{* *} \mathrm{p}<0.01 ;{ }^{* * *} \mathrm{p}<0.001$

Table 5: Path Coefficients

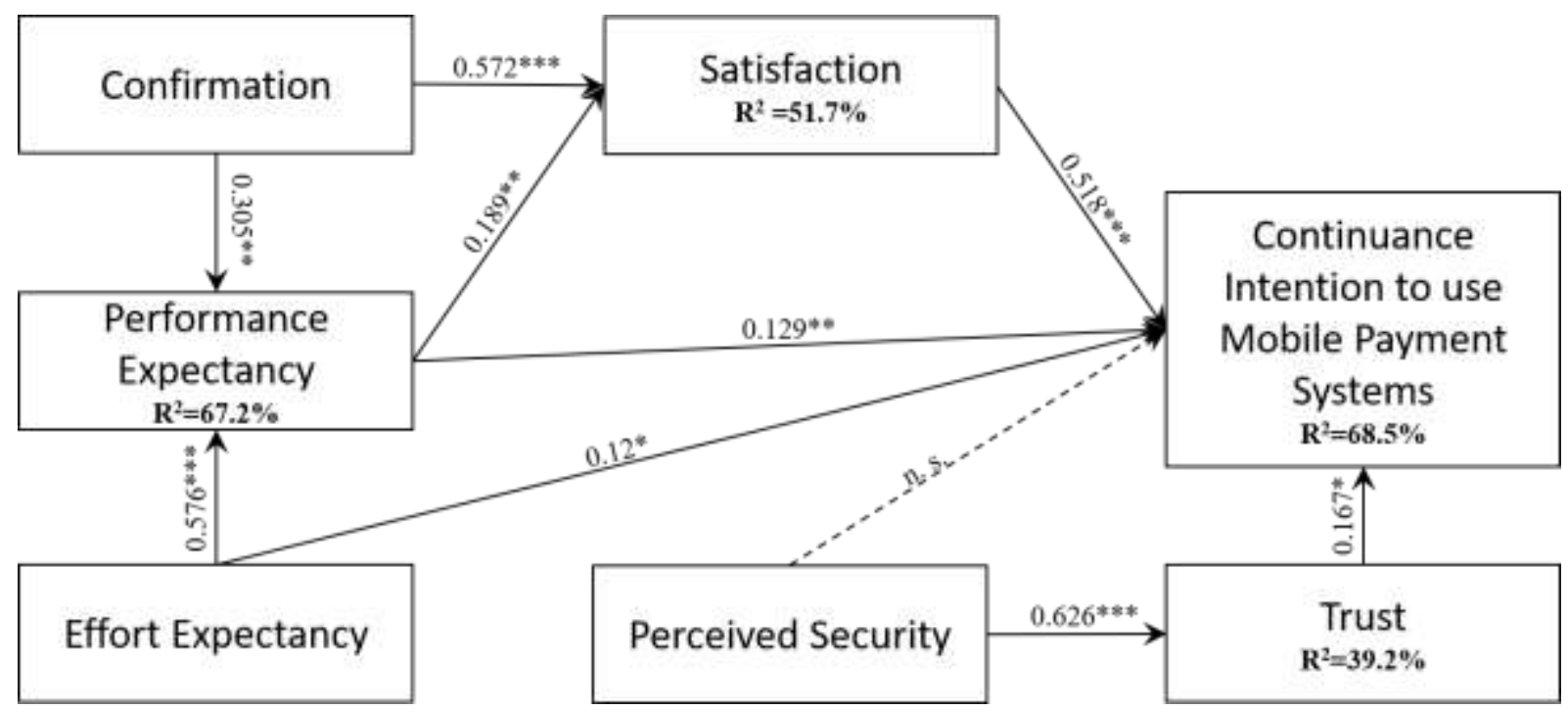

Note: n. s: Not significant; ${ }^{*} \mathrm{p}<0.05 ;{ }^{* *} \mathrm{p}<0.01 ;{ }^{* * *} \mathrm{p}<0.001$

Dotted line indicates non-significant path

\section{Figure 3: Structural Model}

Cohen's f ${ }^{2}$ was calculated (Cohen, 1988) to assess the effect size for all significant paths. The suggested values for $\mathrm{f}^{2}$ are 0.02 for small, 0.15 for medium and 0.35 for large. To assess an exogenous construct's contribution to an endogenous variable's $Q^{2}$ value, $\mathrm{q}^{2}$ was calculated. The $\mathrm{q}^{2}$ values of $0.02,0.15$ and 0.35 indicate that an exogenous construct has small, medium and large predictive relevance to its endogenous construct, respectively. Table 6 shows the effect size and predictive relevance. 


\begin{tabular}{|l|c|l|c|l|}
\hline \multicolumn{1}{|c|}{ Path } & $\mathbf{f}^{\mathbf{2}}$ & Effect Size & $\mathbf{q}^{\mathbf{2}}$ & Effect Size \\
\hline $\mathrm{PE} \rightarrow \mathrm{CI}$ & 0.019 & small & 0.006 & small \\
\hline $\mathrm{EE} \rightarrow \mathrm{CI}$ & 0.016 & small & 0.004 & small \\
\hline $\mathrm{EE} \rightarrow$ PE & 0.524 & large & 0.186 & medium \\
\hline TRUST $\rightarrow$ CI & 0.029 & small & 0.011 & small \\
\hline SAT $\rightarrow$ CI & 0.34 & medium & 0.138 & medium \\
\hline CONF $\rightarrow$ PE & 0.143 & small & 0.054 & small \\
\hline CONF $\rightarrow$ SAT & 0.335 & medium & 0,207 & medium \\
\hline PE $\rightarrow$ SAT & 0.037 & small & 0.023 & small \\
\hline
\end{tabular}

Table 6: Theoretical effect size for $f^{2}$ and $q^{2}$

Stone-Geisser's Q2 (Geisser, 1975; Stone, 1974) value was computed to cross-validate the predictive relevance of the model by running the blindfolding technique with an omission distance of 7. The $\mathrm{Q}^{2}$ values obtained for the endogenous variables continuance intention, performance expectancy, satisfaction and trust were $0.465,0.426,0.396$ and 0.252 , respectively. These are greater than zero, indicating that the model has predictive relevance (Hair, Hult, Ringle, \& Sarstedt, 2016).

\subsection{Mediation Analysis}

To assess the mediation effect in the theoretical model, the bootstrapping method was used. This method does not make any assumption about the sampling distribution, and it works well with small sample sizes (Hair et al., 2016). The variance accounted for (VAF) was used with the following conditions (Hair et al., 2016) to examine the mediation analysis.

$\mathrm{VAF}=$ Indirect effect $/$ Total effect

If the VAF value is less than 0.2 , there is no mediation; if the value is greater than or equal to 0.2 and less than or equal to 0.8 , then there is partial mediation; and if the value is greater than 0.8 , there is full mediation (Hair et al., 2016).

The VAF value was calculated (Table 7) to determine the mediation effect of the variable satisfaction in the relationship between performance expectancy and continuance intention to use mobile payment systems. The VAF value obtained was 0.43 , indicating that satisfaction partially mediated the relationship between performance expectancy and continuance intention. For the mediation effect of satisfaction on the relationship between effort expectancy and continuance intention, the VAF value was 0.22 , showing partial mediation. Satisfaction fully mediated the relationship between confirmation and continuance intention to use mobile payment systems. Performance expectancy partially mediated the relationship between effort expectancy and continuance intention, and fully mediated the relationship between effort expectancy and satisfaction. Trust fully mediated the relationship between perceived security and continuance intention.

\begin{tabular}{|l|l|c|}
\hline \multicolumn{1}{|c|}{ Path } & VAF & Mediation \\
\hline $\mathrm{EE} \rightarrow \mathrm{PE} \rightarrow \mathrm{CI}$ & 0.381 & partial \\
\hline $\mathrm{CONF} \rightarrow \mathrm{PE} \rightarrow \mathrm{SAT} \rightarrow \mathrm{CI}$ & 0.08 & Nil \\
\hline $\mathrm{EE} \rightarrow \mathrm{PE} \rightarrow \mathrm{SAT} \rightarrow \mathrm{CI}$ & 0.22 & partial \\
\hline $\mathrm{CONF} \rightarrow \mathrm{PE} \rightarrow \mathrm{SAT}$ & 0.09 & Nil \\
\hline $\mathrm{CONF} \rightarrow \mathrm{SAT} \rightarrow \mathrm{CI}$ & 0.8 & Full \\
\hline $\mathrm{EE} \rightarrow \mathrm{PE} \rightarrow \mathrm{SAT}$ & 1 & Full \\
\hline $\mathrm{PS} \rightarrow$ Trust $\rightarrow \mathrm{CI}$ & 1 & Full \\
\hline
\end{tabular}

Table 7: Mediation Analysis 


\section{Discussion}

Many studies have examined the initial acceptance of mobile payment systems by users and also various antecedents to initial adoption. However, few studies have addressed postadoption behaviour with respect to these systems. The current study addressed this research gap by investigating post-adoption behaviour towards mobile payment systems using a theoretical framework combining the UTAUT and the ECM. This framework used a quantitative, cross-sectional design, with mobile payment users as the target respondents.

This study combined the UTAUT and the ECM in the integrated model along with two additional constructs: perceived security and trust. The model showed strong empirical support for predicting continuance intention to use mobile payment systems, with an $\mathrm{R}^{2}$ value of 0.685 . The empirical result shows that the integrated model has a high predictive power to explain the continuance intention to use mobile payment systems. Using the UTAUT framework, both performance expectancy and effort expectancy were strong predictors of continuance intention. Performance expectancy, effort expectancy, trust and satisfaction together explained $68.5 \%$ of the variance in the dependent variable: continuance intention to use mobile payment systems. Thus, performance expectancy and effort expectancy are essential predictors not only for initial adoption but also for repeated usage of mobile payment systems. The performance expectancy construct clearly had a significant effect on postadoption expectations through satisfaction as well as acting as a direct antecedent to continuance intention. Performance expectancy is an integrated construct derived from many adoption theories, and it has considerable explanatory power in initial adoption behaviour (Venkatesh et al., 2003; Venkatesh et al., 2012). Through the ECM model, this study empirically demonstrated that performance expectancy represents post-adoption expectations. This implies that the performance of the mobile payment system during the post-adoption phase significantly influences users to continue using it. Users emphasise the importance of usability as a key factor in the success of any mobile payment system.

Furthermore, mobile payment systems should be convenient, meet customers' needs and be available anytime, anywhere. Prior studies have shown that performance expectancy is a significant predictor of the initial adoption of mobile payment systems (Abrahão, Moriguchi, \& Andrade, 2016), and this study confirmed this finding: performance expectancy is a significant predictor, even for continued usage of mobile payment systems. These findings are consistent with Zhou (2014), who also showed that performance expectancy affects continuance intention to use mobile payment systems.

In this study, effort expectancy was a significant predictor of post-adoption behaviour and a direct antecedent to performance expectancy, explaining $67.2 \%$ of the variance. This suggests that customers are looking for user-friendly mobile payment systems in the post-adoption stage. Prior studies have also demonstrated a linkage between effort expectancy and performance expectancy (Tam, Santos, \& Oliveira, 2018). Thus, promotional strategies are helpful only in the initial adoption of mobile payment systems, but it is the user-friendliness of the mobile payment system that encourages repeated usage. Moreover, the effort to use a mobile payment system will improve performance expectations at the post-adoption stage. This study identified key predictors of continuance intention to use mobile payment systems: performance expectancy, effort expectancy, satisfaction and trust. Among these factors, satisfaction had the highest impact on continuance intention, followed by trust. These results validate that satisfied customers are willing to continue using their mobile payment systems. 
The competition in the mobile payment service industries is intense, and users of mobile payment systems have a multitude of choices. Hence, service providers must ensure that users are satisfied with the mobile payment system, which will promote loyalty to the system. Past studies have also pointed out that satisfaction promotes continuance intention (Cao et al., 2018; Zhou, 2013). Trust is the second most important factor in the decision to continue using mobile payment systems. This result underscores the importance of the users' trust expectations for their mobile payment service providers, even after they have been using the systems for a considerable period of time. Perceived security was not significant for predicting continuance intention, but it was a direct antecedent to trust, explaining $39.2 \%$ of the variance. The reason for this finding might be that customers perceive that security is built into the mobile payment systems; hence, they trust these systems. In other words, customers may automatically believe that the security features of their chosen mobile payment systems are adequate for conducting basic financial transactions.

This study empirically demonstrated that the ECM model can be applied in a mobile payment context to explain post-adoption behaviour. Prior studies have used the ECM in other contexts, such as mobile banking (Kumar, Israel, \& Malik, 2018), websites (Zhang et al., 2015) and mobile instant messaging (Oghuma, Libaque-Saenz, Wong, \& Chang, 2016). In this study, the ECM model accounted for $51.7 \%$ of the variance in continuance intention. Furthermore, this study suggested that the ECM model is well suited for explaining customers' post-adoption behaviour with respect to emerging technologies, such as mobile payment systems.

\subsection{Theoretical Implications}

This study makes significant theoretical and practical contributions. The main theoretical contribution of the study is the integration of the UTAUT and the ECM into a single theoretical framework to explain post-adoption behaviour as it relates to mobile payment systems. The UTAUT model was extensively used in earlier studies to shed light on the initial adoption of mobile payment systems (Cao \& Niu, 2019; Teo et al., 2015). This study is among the first to show that the UTAUT model can be extended to post-adoption behaviour towards emerging information systems, such as those for mobile payments. This study empirically showed that trust is a significant predictor in the post-adoption phase of mobile payment systems, which involve financial transactions. Hence, the present study bridges the gap by adding the constructs of trust and perceived security - vital constructs in consumer-centric IS - to the UTAUT model. This extended model has the predictive power to explain post-adoption behaviour even in the case of a cutting-edge technology like mobile payments. Furthermore, the majority of studies on post-adoption behaviour towards mobile payment systems have been in China (Cao et al., 2018; Chen \& Li, 2017; Zhou, 2013). This study was conducted in a different cultural and socioeconomic context, thereby diversifying insights in the existing literature. Existing studies (Fan et al., 2018; Oliveira et al., 2016) have suggested that refining the initial acceptance models by applying them in different countries and demographic groups, to different technologies, and with additional constructs, will strengthen the explanatory power of the models.

\subsection{Practical Implications}

This study's findings have many practical implications. First, the factors that have been found to be important in post-adoption can be exploited by financial institutions to increase the growth of mobile payment systems. The empirical results showed that satisfied customers are willing to continue with their mobile payment services, and this suggests that service 
providers should focus on improving their service delivery processes to retain their customer base and survive in the highly competitive mobile payment market. Also, service providers should introduce various incentives and discounts to attract customers from different segments. The findings also revealed that even in the post-adoption stage, customers place considerable importance on performance expectancy and effort expectancy factors. Thus, information technology developers who create mobile payment apps should develop straightforward, user-friendly interfaces. To emphasise the usability of mobile payment systems, service providers should develop promotional strategies to generate awareness among potential customers. Another important finding of the study that is applicable to practitioners is the significance of trust. For trust building, service providers should implement appropriate security mechanisms, policies and frameworks, as well as customer redressal systems. Regarding this finding, demographic factors such as age, gender and income did not influence continuance intention. Service providers can use these results to craft mobile payment solutions that will appeal to all segments of their customer base.

\subsection{Limitations and Future Research}

The present study has some limitations that have the potential to be addressed by future research. The first limitation is that the sample was drawn from a metropolitan area, whereas future studies could sample both urban and rural populations. Moreover, this study used convenience sampling; thus, caution should be used when interpreting and generalising the findings. Another limitation of the study is that hedonic factors were not included in the theoretical model. Future research could incorporate hedonic factors into the UTAUT2 theoretical framework to better explain post-adoption behaviour towards mobile payment systems. Finally, only a limited number of studies have addressed the post-adoption behaviour of mobile payment systems. Hence, future research should focus more on theoretical frameworks and empirical findings in this understudied area.

\section{Conclusion}

Technological progression in mobile phones has prompted rapid growth in mobile payment systems and usage, with e-commerce sites, in-store payments and utilities widely adopting these systems. Pre-adoption of mobile payment systems has been studied extensively, but few studies have shed light on post-adoption behaviour. This study applied an integrated model combining the UTAUT and the ECM and identified factors such as satisfaction, trust, performance expectancy and effort expectancy. This study confirmed that the UTAUT model can be extended to study post-adoption behaviour towards mobile payment systems. The study's findings have both theoretical and practical value for furthering the understanding of pre- and post-adoption behaviour with respect to mobile payments.

\section{References}

Abrahão, R. D., Moriguchi, S. N., \& Andrade, D. F. (2016). Intention of adoption of mobile payment: An analysis in the light of the Unified Theory of Acceptance and Use of Technology (UTAUT). RAI Revista de Administração e Inovação, 13(3), 221-230. doi:10.1016/j.rai.2016.06.003

Adhikary, S. (2018). Digital Consumer Profiles: How India's Most Digitally Savoy Will Shop and Spend Online (pp. 1-48). Euromonitor International. 
Anderson, J. C., \& Gerbing, D. W. (1988). Structural equation modeling in practice: A review and recommended two-step approach. Psychological Bulletin, 103(3), 411-423.

Anderson, R., \& Srinivasan, S. (2003). E-satisfaction and e-loyalty: A contingency framework. Psychology \& Marketing,20(2), 123-138.

Apanasevic, T., Markendahl, J., \& Arvidsson, N. (2016). Stakeholders ' expectations of mobile payment in retail: lessons from Sweden. International Journal of Bank Marketing, 34(1), 3761.

Baabdullah, A., Alalwan, A., Rana, N., Kizgin, H., \& Patil, P. (2019). Consumer use of mobile banking (M-Banking) in Saudi Arabia: Towards an integrated model. International Journal of Information Management, 44, 38-52.

Bailey, A. A., Pentina, I., Mishra, A. S., \& Ben Mimoun, M. S. (2017). Mobile payments adoption by US consumers: an extended TAM. International Journal of Retail $\mathcal{E}$ Distribution Management, 45(6), 626-640. doi:10.1108/ijrdm-08-2016-0144

Bhattacherjee, A. (2001). Understanding Information Systems Continuance: An ExpectationConfirmation Model. MIS Quarterly, 25(3), 351.

Byrne, B. M. (2016). Structural equation modeling with AMOS: Basic concepts, applications, and programming (3rd ed.). Routledge.

Cao, X., Yu, L., Liu, Z., Gong, M., \& Adeel, L. (2018). Understanding mobile payment users' continuance intention: a trust transfer perspective. Internet Research, 28(2), 456-476.

Cao, Q., \& Niu, X. (2019). Integrating context-awareness and UTAUT to explain Alipay user adoption. International Journal of Industrial Ergonomics, 69, 9-13.

Chen, X., \& Li, S. (2017). Understanding Continuance Intention of Mobile Payment Services: An Empirical Study. Journal Of Computer Information Systems, 57(4), 287-298.

Chin, W., Marcolin, B., \& Newsted, P. (2003). A Partial Least Squares Latent Variable Modeling Approach for Measuring Interaction Effects: Results from a Monte Carlo Simulation Study and an Electronic-Mail Emotion/Adoption Study. Information Systems Research, $14(2), 189-217$.

Cohen, J. (1988). Statisticalpower analysis for the behavioral sciences (2'EU.). HillsUale, NJ: Lawrence Eribaum Associates.

Dahlberg, T., Mallat, N., Ondrus, J., \& Zmijewska, A. (2008). Past, present and future of mobile payments research: A literature review. Electronic Commerce Research and Applications, $7(2), 165-181$.

Delone, W., \& McLean, E. (2003). The DeLone and McLean Model of Information Systems Success: A Ten-Year Update. Journal of Management Information Systems, 19(4), 9-30.

Dwivedi, Y. K., Rana, N. P., Jeyaraj, A., Clement, M., \& Williams, M. D. (2017). Re-examining the Unified Theory of Acceptance and Use of Technology (UTAUT): Towards a Revised Theoretical Model. Information Systems Frontiers, 21(3), 719-734. doi:10.1007/s10796-0179774-y

Fan, J., Shao, M., Li, Y., \& Huang, X. (2018). Understanding users' attitude toward mobile payment use. Industrial Management \& Data Systems, 118(3), 524-540. doi:10.1108/imds06-2017-0268 
Fornell, C., \& Larcker, D. (1981). Evaluating structural equation models with unobservable variables and measurement error. Journal of Marketing Research, 39-50.

Garland, R. (1991). The mid-point on a rating scale: Is it desirable. Marketing Bulletin,2(1), 6670 .

Gerban, M. (2019). Mobile Wallet Trends (Rep.). Retrieved May 25, 2019, from Global Acceptance Transaction Engine(GATE) website: https://www.poweredbygate.com/wpcontent/uploads/2019/03/GATE-Mobile-Wallet-Trends-Final-03.26.19.pdf

Geisser, S. (1974). A Predictive Approach to the Random Effect Model. Biometrika,61(1), 101107.

George, D., \& Mallery, M. (2010). SPSS for Windows Step by Step: A Simple Guide and Reference, 17.0 update 10/e.

Ghezzi, A., Renga, F., Balocco, R., \& Pescetto, P. (2010). Mobile payment applications: offer state of the art in the Italian market. Info, 12(5), 3-22.

Giovanis, A., Assimakopoulos, C., \& Sarmaniotis, C. (2018). Adoption of mobile self-service retail banking technologies. International Journal of Retail $\mathcal{E}$ Distribution Management.

Hair, J. F., Black, W. C., Babin, B. J., \& Anderson, R. E. (2010). Multivariate data analysis. Pearson Higher Ed.

Hair Jr, J. F., Hult, G. T. M., Ringle, C., \& Sarstedt, M. (2016). A primer on partial least squares structural equation modeling (PLS-SEM). Sage publications.

Hair, J. F., Risher, J. J., Sarstedt, M., \& Ringle, C. M. (2019). When to use and how to report the results of PLS-SEM. European Business Review, 31(1), 2-24. doi:10.1108/ebr-11-2018-0203.

Hair, J. F., Sarstedt, M., \& Ringle, C. M. (2019). Rethinking some of the rethinking of partial least squares. European Journal of Marketing, 53(4), 566-584. doi:10.1108/ejm-10-2018-0665.

Hampshire, C. (2017). A mixed methods empirical exploration of UK consumer perceptions of trust, risk and usefulness of mobile payments. International Journal of Bank Marketing, 35(3), 354-369.

Hoque, R., \& Sorwar, G. (2017). Understanding factors influencing the adoption of mHealth by the elderly: An extension of the UTAUT model. International Journal of Medical Informatics, 101, 75-84.

Iman, N. (2018). Is mobile payment still relevant in the fintech era?. Electronic Commerce Research And Applications, 30, 72-82.

Isaac, J. T., \& Sherali, Z. (2014). Secure mobile payment systems. IT Professional, 16(3), 36-43.

José Liébana-Cabanillas, F., Sánchez-Fernández, J., \& Muñoz-Leiva, F. (2014). Role of gender on acceptance of mobile payment. Industrial Management \& Data Systems, 114(2), 220-240.

Kang, J. (2018). Mobile payment in Fintech environment: Trends, security challenges, and services. Human-centric Computing and Information Sciences, 8(32), 1-16. doi:10.1186/s13673-018-0155-

Khalilzadeh, J., Ozturk, A., \& Bilgihan, A. (2017). Security-related factors in extended UTAUT model for NFC based mobile payment in the restaurant industry. Computers In Human Behavior, 70, 460-474. 
Kim, C., Mirusmonov, M., \& Lee, I. (2010). An empirical examination of factors influencing the intention to use mobile payment. Computers in Human Behavior, 26(3), 310-322. doi:10.1016/j.chb.2009.10.013

Kline, R. B. (2011). Principles and practice of structural equation modeling. Guilford Press.

Kumar, A., Adlakaha, A., \& Mukherjee, K. (2018). The effect of perceived security and grievance redressal on continuance intention to use M-wallets in a developing country. International Journal of Bank Marketing, 36(7), 1170-1189. doi:10.1108/ijbm-04-2017-0077

Kumar, R. R., Israel, D., \& Malik, G. (2018). Explaining customer's continuance intention to use mobile banking apps with an integrative perspective of ECT and Self-determination theory. Pacific Asia Journal of the Association for Information Systems,79-112.

Lee, J., Cho, C., \& Jun, M. (2011). Secure quick response-payment (QR-Pay) system using mobile device. In 13th International Conference on In Advanced Communication Technology (ICACT) (pp. 1424-1427). IEEE.

Li, H., Liu, Y., \& Heikkilä, J. (2014). Understanding the Factors Driving NFC-Enabled Mobile Payment Adoption: an Empirical Investigation. PACIS, 231-244.

Lu, J., Wei, J., Yu, C., \& Liu, C. (2016). How do post-usage factors and espoused cultural values impact mobile payment continuation? Behaviour $\mathcal{E}$ Information Technology, 36(2), 140-164. doi:10.1080/0144929x.2016.1208773

Mayer, R., Davis, J., \& Schoorman, F. (1995). An integrative model of organizational trust. Academy of Management Review, 20(3), 709-734.

Mcknight, D. H., Choudhury, V., \& Kacmar, C. (2002). Developing and Validating Trust Measures for e-Commerce: An Integrative Typology. Information Systems Research, 13(3), 334-359.

Mobile Payments World. (2019). Retrieved May 19, 2019, from https://www.mobilepaymentsworld.com/

Musa, A., Khan, H. U., \& AlShare, K. A. (2015). Factors influence consumers' adoption of mobile payment devices in Qatar. International Journal of Mobile Communications, 13(6), 670. doi:10.1504/ijmc.2015.072100

Oghuma, A. P., Libaque-Saenz, C. F., Wong, S. F., \& Chang, Y. (2016). An expectationconfirmation model of continuance intention to use mobile instant messaging. Telematics and Informatics,33(1), 34-47.

Oliveira, T., Thomas, M., Baptista, G., \& Campos, F. (2016). Mobile payment: Understanding the determinants of customer adoption and intention to recommend the technology. Computers In Human Behavior, 61, 404-414.

Oliver, R. L. (1997). Satisfaction a behavioral perspective on the consumer. Oxfordshire: Routledge.

Ondrus, J., \& Pigneur, Y. (2006). Towards a holistic analysis of mobile payments: A multiple perspectives approach. Electronic Commerce Research and Applications, 5(3), 246-257.

Orr, G. (2010, April). A review of literature in mobile learning: Affordances and constraints. In 2010 6th IEEE International Conference on Wireless, Mobile, and Ubiquitous Technologies in Education (pp. 107-111). IEEE. 
Phonthanukitithaworn, C., Sellitto, C., \& Fong, M. (2015). User intentions to adopt mobile payment services: A study of early adopters in Thailand. Journal Of Internet Banking And Commerce, 20(1), 1-29.

Podsakoff, P., MacKenzie, S., Lee, J., \& Podsakoff, N. (2003). Common method biases in behavioral research: A critical review of the literature and recommended remedies. Journal Of Applied Psychology, 88(5), 879-903.

Ramadan, R., \& Aita, J. (2018). A model of mobile payment usage among Arab consumers. International Journal of Bank Marketing, 36(7), 1213-1234. doi:10.1108/ijbm-05-2017-0080

Ringle, C. M., Silva, D. D., \& Bido, D. D. (2014). Structural Equation Modeling with the Smartpls. Revista Brasileira De Marketing,13(02), 56-73.

Schierz, P. G., Schilke, O., \& Wirtz, B. W. (2010). Understanding consumer acceptance of mobile payment services: An empirical analysis. Electronic Commerce Research and Applications, 9(3), 209-216. doi:10.1016/j.elerap.2009.07.005

Shang, D., \& Wu, W. (2017). Understanding mobile shopping consumers' continuance intention. Industrial Management \& Data Systems, 117(1), 213-227.

Stone, M. (1974). Cross-Validatory Choice and Assessment of Statistical Predictions (With Discussion). Journal of the Royal Statistical Society: Series B (Methodological),38(1), 111-147.

Susanto, A., Chang, Y., \& Ha, Y. (2016). Determinants of continuance intention to use the smartphone banking services. Industrial Management \& Data Systems, 116(3), 508-525.

Tam, C., Santos, D., \& Oliveira, T. (2018). Exploring the influential factors of continuance intention to use mobile Apps: Extending the expectation confirmation model. Information Systems Frontiers,1-15.

Tellez Isaac, J., \& Sherali, Z. (2014). Secure Mobile Payment Systems. IT Professional, 16(3), 3643.

Teo, A., Tan, G., Ooi, K., Hew, T., \& Yew, K. (2015). The effects of convenience and speed in m-payment. Industrial Management \& Data Systems, 115(2), 311-331.

Venkatesh, V., Thong, J., \& Xu, X. (2012). Consumer Acceptance and Use of Information Technology: Extending the Unified Theory of Acceptance and Use of Technology. MIS Quarterly, 36(1), 157-178.

Venkatesh, V., Morris, M., Davis, G., \& Davis, F. (2003). User Acceptance of Information Technology: Toward a Unified View. MIS Quarterly, 27(3), 425-478.

Wang, Y., Hahn, C., \& Sutrave, K. (2016). Mobile payment security, threats, and challenges. 2016 Second International Conference on Mobile and Secure Services (MobiSecServ)IEEE, 1-5. doi:10.1109/mobisecserv.2016.7440226.

Yuan, S., Liu, Y., Yao, R., \& Liu, J. (2014). An investigation of users' continuance intention towards mobile banking in China. Information Development, 32(1), 20-34. doi:10.1177/0266666914522140

Zhang, H., Lu, Y., Gupta, S., \& Gao, P. (2015). Understanding group-buying websites continuance. Internet Research, 25(5), 767-793. 
Zhou, T. (2014). Understanding the determinants of mobile payment continuance usage. Industrial Management \& Data Systems, 114(6), 936-948.

Zhou, T. (2013). An empirical examination of continuance intention of mobile payment services. Decision Support Systems, 54(2), 1085-1091. 


\section{Appendix A:}

Construct and their sources

\begin{tabular}{|c|c|c|c|}
\hline Constructs & Items & & Source \\
\hline \multirow[t]{4}{*}{$\begin{array}{l}\text { Continuance intention } \\
\text { to use }(\mathrm{CI})\end{array}$} & CI1 & $\begin{array}{l}\text { I plan to use mobile payment } \\
\text { services more often. }\end{array}$ & \multirow[t]{4}{*}{$\begin{array}{l}\text { Chen \& Li } \\
(2017)\end{array}$} \\
\hline & CI2 & $\begin{array}{l}\text { Mobile payment services currently } \\
\text { are and also will be one of my } \\
\text { commonly used payment methods. }\end{array}$ & \\
\hline & $\mathrm{CI} 3$ & $\begin{array}{l}\text { I intend to continue using mobile } \\
\text { payment services. }\end{array}$ & \\
\hline & CI4 & $\begin{array}{l}\text { Mobile payments are growing, and } \\
\text { are expected to continue. }\end{array}$ & \\
\hline \multirow[t]{3}{*}{ Satisfaction(SAT) } & SAT1 & $\begin{array}{l}\text { I am delighted with my overall } \\
\text { experience with mobile payment } \\
\text { services. }\end{array}$ & \multirow[t]{3}{*}{$\begin{array}{l}\text { Kumar, Israel, \& } \\
\text { Malik(2018) }\end{array}$} \\
\hline & SAT2 & $\begin{array}{l}\text { I feel contented about my overall } \\
\text { experience with mobile payment } \\
\text { services. }\end{array}$ & \\
\hline & SAT3 & $\begin{array}{l}\text { I am satisfied with my overall } \\
\text { experience with mobile payment } \\
\text { services. }\end{array}$ & \\
\hline \multirow[t]{3}{*}{ Confirmation(CONF) } & CONF1 & $\begin{array}{l}\text { My experience with mobile payment } \\
\text { services was better than what I } \\
\text { expected. }\end{array}$ & \multirow[t]{3}{*}{$\begin{array}{l}\text { Bhattacherjee } \\
\text { (2001) }\end{array}$} \\
\hline & CONF2 & $\begin{array}{l}\text { The various features of mobile } \\
\text { payment services was better than } \\
\text { what I expected. }\end{array}$ & \\
\hline & CONF3 & $\begin{array}{l}\text { Overall, most of my expectations } \\
\text { towards mobile payment services } \\
\text { were confirmed. }\end{array}$ & \\
\hline $\begin{array}{l}\text { Performance } \\
\text { expectancy(PE) }\end{array}$ & PE1 & $\begin{array}{l}\text { I would find that mobile payment } \\
\text { services are useful for me. }\end{array}$ & $\begin{array}{l}\text { Venkatesh et al. } \\
(2003)\end{array}$ \\
\hline
\end{tabular}




\begin{tabular}{|c|c|c|c|}
\hline & PE2 & $\begin{array}{l}\text { Using the mobile payment services } \\
\text { enables me to accomplish tasks } \\
\text { quickly compared to traditional } \\
\text { payment systems. }\end{array}$ & \\
\hline & PE3 & $\begin{array}{l}\text { Using the mobile payment services } \\
\text { increases my productivity. }\end{array}$ & \\
\hline & PE4 & $\begin{array}{l}\text { Overall I will find mobile payment } \\
\text { services useful in my payment } \\
\text { transactions. }\end{array}$ & \\
\hline Effort expectancy(EE) & EE1 & $\begin{array}{l}\text { I would find it easy to use mobile } \\
\text { payment services to accomplish my } \\
\text { payment. }\end{array}$ & $\begin{array}{l}\text { Venkatesh et al. } \\
\text { (2003) }\end{array}$ \\
\hline & EE2 & $\begin{array}{l}\text { My interaction with mobile payment } \\
\text { services would be clear and } \\
\text { understandable. }\end{array}$ & \\
\hline & EE3 & $\begin{array}{l}\text { It would be easy for me to become } \\
\text { skillful of using mobile payment } \\
\text { services. }\end{array}$ & \\
\hline & EE4 & $\begin{array}{l}\text { Learning to operate the mobile } \\
\text { payment services is easy for me. }\end{array}$ & \\
\hline Perceived security(PS) & PS1 & $\begin{array}{l}\text { The risk of an unauthorized third } \\
\text { party overseeing the payment } \\
\text { process is low. }\end{array}$ & $\begin{array}{l}\text { Schierz, Schilke, } \\
\& \text { Wirtz (2010) }\end{array}$ \\
\hline & PS2 & $\begin{array}{l}\text { The risk of abuse of usage } \\
\text { information (e.g., names of business } \\
\text { partners, payment amount) is low } \\
\text { when using mobile payment } \\
\text { services. }\end{array}$ & \\
\hline & PS3 & $\begin{array}{l}\text { The risk of abuse of billing } \\
\text { information (e.g., credit card } \\
\text { number, bank account data) is low } \\
\text { when using mobile payment } \\
\text { services. }\end{array}$ & \\
\hline
\end{tabular}




\begin{tabular}{|c|c|c|c|}
\hline & PS4 & $\begin{array}{l}\text { I would find mobile payment } \\
\text { services secure in conducting my } \\
\text { payment transactions. }\end{array}$ & \\
\hline \multirow[t]{6}{*}{ Trust(TRU) } & TRU1 & $\begin{array}{l}\text { I believe the technology of mobile } \\
\text { payment services is secured. }\end{array}$ & \multirow[t]{6}{*}{$\begin{array}{l}\text { Chen \& } \\
(2017)\end{array}$} \\
\hline & TRU2 & $\begin{array}{l}\text { I believe the technology of mobile } \\
\text { payment services is reliable. }\end{array}$ & \\
\hline & TRU3 & $\begin{array}{l}\text { I believe the technology of mobile } \\
\text { payment services is worthy of trust. }\end{array}$ & \\
\hline & TRU4 & $\begin{array}{l}\text { I believe mobile payment services } \\
\text { providers would keep their } \\
\text { commitments. }\end{array}$ & \\
\hline & TRU5 & $\begin{array}{l}\text { I believe mobile payment services } \\
\text { providers would act in users' best } \\
\text { interest. }\end{array}$ & \\
\hline & TRU6 & $\begin{array}{l}\text { I would believe mobile payment } \\
\text { services providers as honest. }\end{array}$ & \\
\hline
\end{tabular}

Copyright: (C) 2020 Singh. This is an open-access article distributed under the terms of the Creative Commons Attribution-NonCommercial 3.0 Australia License, which permits noncommercial use, distribution, and reproduction in any medium, provided the original author and AJIS are credited.

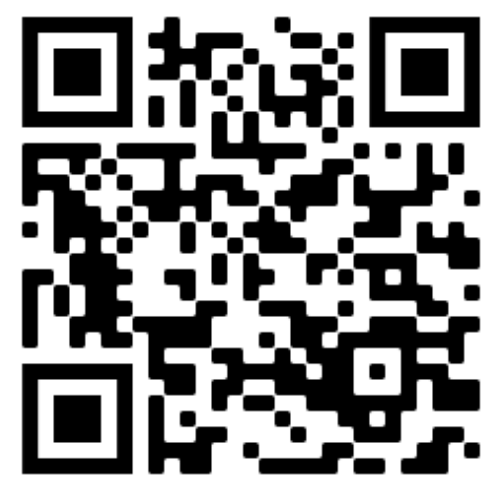

